\title{
Highlights from the European Respiratory Society 2017 annual congress: epidemiology and environment (assembly 6)
}

\author{
Ane Aamli Gagnat ${ }^{1}$, André F. S. Amaral ${ }^{2}$ \\ ${ }^{1}$ Department of Clinical Science, University of Bergen, Bergen, Norway; ${ }^{2}$ Population Health and Occupational Disease, National Heart and Lung \\ Institute, Imperial College London, London, UK \\ Correspondence to: Ane Aamli Gagnat. Department of Clinical Science, University of Bergen, Bergen, Norway. Email: aneaamli@hotmail.com.
}

Submitted Aug 17, 2017. Accepted for publication Sep 29, 2017.

doi: $10.21037 /$ jtd.2017.11.33

View this article at: http://dx.doi.org/10.21037/jtd.2017.11.33

\section{How do smokers quit?}

Vardavas et al. provided information on trends in and patterns of smoking cessation methods used in the EU between 2012 and 2014 (1). The authors analysed data from the 'Special Eurobarometer for Tobacco survey'. The survey data allows analyses which focus on changes in use of smoking cessation methods. The authors evaluated whether smoking cessation methods differed by sociodemographic characteristics. Several methods to quit smoking were applied less frequently over time: quitting without assistance; use of nicotine replacement therapy; healthcare professionals; and smoking cessation clinics. However, experimentation with e-cigarettes for the purpose of quitting increased, especially among younger people and those with a lower income. Interestingly, these changes were not consistent across EU member states.

As a conclusion, the authors suggest that a common evidence-based strategy to smoking cessation should be implemented across EU. Will this ever happen?

\section{Smoke-free laws: have they reduced second- hand smoking?}

Today, indoor air in public and work spaces is cleaner and life satisfaction is higher (2) - thanks to the European smoking ban! Most of the EU countries have implemented smokefree environments to reduce exposure to second-hand smoke (SHS). However, it is not clear whether the smoking ban led to a reduction in SHS exposure. Filippidis et al. compared SHS exposure in 27,788 people, aged 15 years or more, in 2009 to 27,801 people, of the same age, in 2014 in $28 \mathrm{EU}$ countries.
They found a significant $20 \%$ reduction in exposure to SHS in public places such as bars and restaurants, over the five-year period (3). However, the proportion of individuals exposed to SHS in the workplace increased by about $4 \%$ over the same period. The findings of this study reveal that many people in the EU continue to be exposed to SHS, and that the enforcement of smoke-free laws in the workplace is not completely adequate.

\section{Can an airway challenge test predict chronic obstructive pulmonary disease (COPD)?}

Measured with a challenge test and defined by a response beyond normal of the airways to nonspecific constrictor stimuli (4), airway hyper-responsiveness is a characteristic feature of asthma that is common among COPD patients too (5). Whether this feature precedes or is a consequence of COPD is unclear. Marcon et al. (6) explored this question by assessing the association of airway hyperresponsiveness with incident COPD in over 3,000 young and middle-aged adults from the multi-centre populationbased European Community Respiratory Health Survey 2 (ECRHS2) $(4,7)$, who were followed up for about 10 years (ECRHS3). The challenge test was carried out using methacholine, and airway responsiveness was treated either as categorical or continuous variable. COPD was defined using the ratio of forced expiratory volumeone second (FEV1) to forced vital capacity (FVC) either as binomial or continuous variable. They found that participants with airway hyper-responsiveness were more than twice more likely to develop COPD than those without airway hyper-responsiveness. This association was 
evident also in a dose-response manner.

Despite some loss to follow up and changes in the spirometry protocol [i.e., pre-bronchodilator at ECRHS2 vs. post-bronchodilator at ECRHS3 (8)], the findings of this study suggest that: (I) airway hyper-responsiveness precedes COPD; and (II) an airway challenge test could be used to identify subjects at risk of COPD. Nevertheless, replication of these findings in independent cohorts is warranted.

\section{Is there a role for DNA methylation in the association of airflow obstruction with occupational exposures?}

Occupational exposures may account for $15-20 \%$ of the burden of COPD in the general population (9), and the mechanism underlying this association is thought to involve the release of free radicals leading to inflammation in the airways (10). van der Plaat $e t$ al. assessed whether the effect of occupational exposures (i.e., biological dust, mineral dust, gases/fumes) on airflow obstruction is mediated by DNA methylation (11). Instead of focusing their analysis on oxidative stress and inflammation-related genes, they carried out an epigenome-wide study (with Illumina's Infinium HumanMethylation450 BeadChip) on almost 1,600 participants from the Dutch LifeLines populationbased cohort (12), who had pre-bronchodilator spirometry readings. They used bootstrapping to test the amount of mediation attributed to DNA methylation. None of the over 420,000 single CpGs (cytosine-phosphate-guanine sites) associated with any of the exposures at the genomewide significance level. However, the exposures did associate with several differential methylated regions, some of which related to immune response.

The findings of this study suggest that the association of airflow obstruction with occupational exposure to dusts, gases and fumes is mediated by DNA methylation. What does this mean? Replication and further research is needed in this field.

\section{Parabens, oral microbiome and lung function. What is this all about?}

Epidemiological evidence suggests that airways obstructive disease may be somehow affected by poor oral health $(13,14)$. One way of preventing the latter is to frequently brush the teeth and use an antibacterial mouthwash, which may or may not contain parabens. These chemicals have biocidal properties and for this characteristic they are widely used in cosmetics and personal hygiene products (e.g., toothpaste and mouthwash). To understand the relationships between the oral microbiome (i.e., genomes of microorganisms present inside the oral cavity), exposure to parabens, and lung function, Bertelsen et al. (15) analysed data from almost 300 Norwegian young adults, who took part in the RHINESSA study and had provided lung function measurements and samples of gingival fluid (for sequencing of the oral microbiome) and urine (for the levels of exposure to parabens). Consistent with other studies (16), parabens were found in more than $94 \%$ of the participants, and women showed higher concentrations than men. Bertelsen et al. showed that the different levels of urinary parabens correlated with the abundance of bacteria of two genera (Enterobacter and Fretibacterium). They found that the greater the microbiome diversity, the better the lung function of women, but not of men. Could this be a sex difference or just the result of the small study sample and insufficient control for confounders?

The authors of this study suggest that exposure to antibacterial chemicals, such as parabens, may modify the association between oral microbiome and lung function. However, how the associations 'parabens-bacteria' and 'bacteria-lung function' interlock with each other is not clear yet. Replication in a larger sample, with prospectively collected data, and further research will surely bring valuable information on this topic.

\section{Acknowledgements}

None.

\section{Footnote}

Conflicts of Interest: The authors have no conflicts of interest to declare.

\section{References}

1. Vardavas C, Filippidis F, Laverty A, et al. Smoking Cessation in Europe: Trends in methods used in the European Union between 2012 and 2014. Eur Respir J 2017;50:PA1272.

2. Rajani NB, Vlachantoni IT, Vardavas CI, et al. The association between occupational secondhand smoke exposure and life satisfaction among adults in the European Union. Tobacco Induced Diseases 2017;15:19.

3. Filippidis FT, Vardavas CI. Trends in exposure to secondhand smoke in the European Union, 2009-2014. Eur 
Respir J 2017;50:PA1252.

4. O'Byrne PM, Inman MD. Airway hyperresponsiveness. Chest 2003;123:411S-6S.

5. Cockcroft DW, Wenzel S. Airway hyperresponsiveness and chronic obstructive pulmonary disease outcomes. J Allergy Clin Immunol 2016;138:1580-1.

6. Marcon A, Locatelli F, Cerveri I, et al. An airway challenge test can predict COPD: an international cohort study. Eur Respir J 2017;50:OA1784.

7. European Community Respiratory Health Survey IISC. The European Community Respiratory Health Survey II. Eur Respir J 2002;20:1071-9.

8. Ekstrom M, Schioler L, Gronseth R, et al. Absolute values of lung function explain the sex difference in breathlessness in the general population. Eur Respir J 2017;49. pii: 1602047.

9. Balmes JR. Occupational contribution to the burden of chronic obstructive pulmonary disease. J Occup Environ Med 2005;47:154-60.

10. Doelman CJ, Leurs R, Oosterom WC, et al. Mineral dust exposure and free radical-mediated lung damage. Exp Lung Res 1990;16:41-55.

11. van der Plaat D, de Vries M, van Gemert SB, et al.

Cite this article as: Gagnat AA, Amaral AF. Highlights from the European Respiratory Society 2017 annual congress: epidemiology and environment (assembly 6). J Thorac Dis 2017;9(Suppl 16):S1554-S1556. doi: 10.21037/jtd.2017.11.33
DNA methylation mediates the association between occupational exposures and lung function. Eur Respir J 2017;50:OA2946.

12. de Jong K, Boezen HM, Kromhout H, et al. Pesticides and other occupational exposures are associated with airway obstruction: the LifeLines cohort study. Occup Environ Med 2014;71:88-96.

13. Gómez Real F, Pérez Barrionuevo L, Franklin K, et al. The Association of Gum Bleeding with Respiratory Health in a Population Based Study from Northern Europe. PLoS One 2016;11:e0147518.

14. Chung JH, Hwang HJ, Kim SH, et al. Associations Between Periodontitis and Chronic Obstructive Pulmonary Disease: The 2010 to 2012 Korean National Health and Nutrition Examination Survey. J Periodontol 2016;87:864-71.

15. Bertelsen R, Ringel-Kulka T, Peddada S, et al. Oral microbiome and associations with chemical exposure, asthma and lung function. Eur Respir J 2017;50:OA321.

16. Calafat AM, Ye X, Wong LY, et al. Urinary concentrations of four parabens in the U.S. population: NHANES 20052006. Environ Health Perspect 2010;118:679-85. 